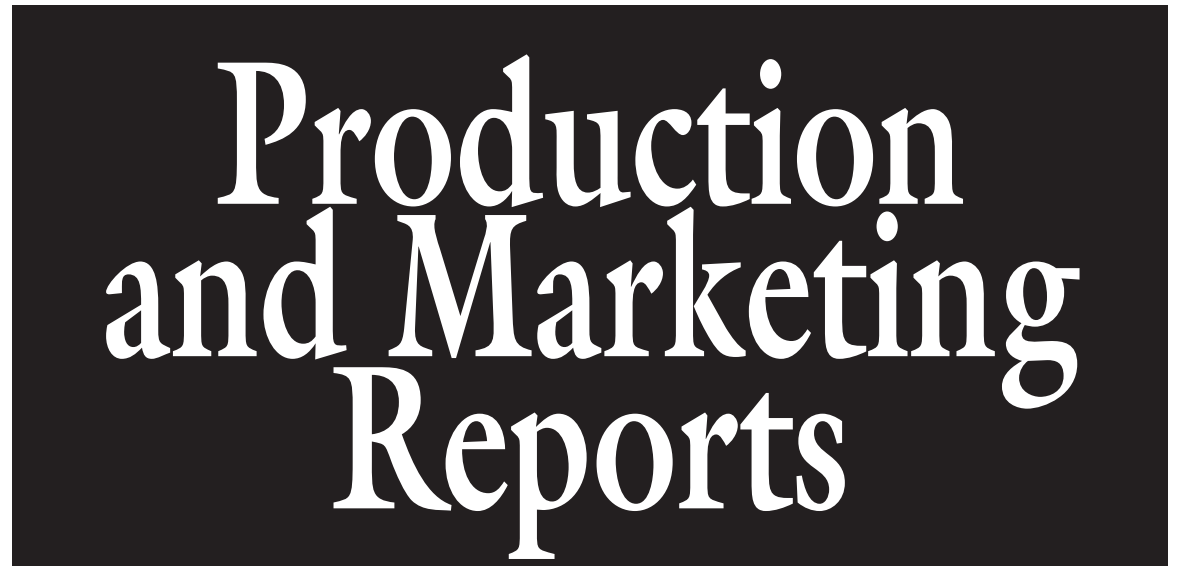

\title{
The Occurrence of Codling Moth in Low Latitude Countries: Validation of Pest Distribution Reports
}

\author{
Michael J. Willett ${ }^{1,4}$, Lisa Neven ${ }^{2}$, and Charles E. Miller ${ }^{3}$
}

AdDitional INDEX words. Malus $\times$ domestica, Cydia pomonella, risk analysis, tropics, subtropics, phytosanitary, diapause, Taiwan

SumMary. Phytosanitary restrictions are increasingly a factor in the ability of U.S. tree fruit exporters to gain and maintain access to worldwide markets. Under international trade rules, these restrictions must be based on specific guidelines, including an assessment of whether the proposed quarantine pest is likely to establish and spread under the climatic conditions of the importing country. Given the interest in and growth of temperate fruit production in the tropics, countries in the region (such as Taiwan, Columbia, Indonesia, and Thailand) have begun to impose a range of quarantine restrictions aimed at preventing the introduction of temperate zone pests. Apples (Malus $\times$ domestica) are regulated in certain tropical/ subtropical countries, such as Taiwan, for the presence of codling moth (CM; Cydia pomonella) in spite of reports in the literature that the distribution of $\mathrm{CM}$ is theoretically limited by daylength and chilling requirements to temperate regions. This work provides background as to why CM has been identified as a potential pest of quarantine concern in some low latitude countries; describes an approach used to validate worldwide $\mathrm{CM}$ distribution reports, providing additional information to allow for the revision of CM distribution maps; and demonstrates how accurate information regarding pest species distribution reports can aid in establishing an argument of ecological nonadaptability in the pest risk analysis process. Currently, a report of CM in Peru remains the only account of this pest's presence in low latitude countries that could not be refuted by the approach described here.

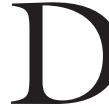
eciduous tree fruit growers in the Pacific northwestern United States of Idaho, Oregon, and Washington export about

\footnotetext{
We thank Nan Lee of the GoodFruit Grower for her assistance in preparing the map of worldwide codling moth distribution and those reviewers who gave their time to improve this contribution.
}

${ }^{1}$ Northwest Horticultural Council, 105 South 18th Street, Suite 105, Yakima, WA 98901.

${ }^{2}$ United States Department of Agriculture, Agricultural Research Service, Yakima Agricultural Research Laboratory, 5230 Konnowac Pass Road, Wapato, WA 98951.

37939 Devilbiss Bridge Road, Frederick, MD 21701.

${ }^{4}$ Corresponding author. E-mail: willett@nwhort.org.
$30 \%$ of the apples produced in the region to over 50 countries around the world [Northwest Horticultural Council (NHC), 2008]. Since the establishment of rules governing the application of international sanitary and phytosanitary (SPS) measures in 1994 [World Trade Organization (WTO), 2009], restrictions aimed at preventing the unwanted introduction of pest species have become more important when seeking to gain or maintain access to specific markets. These restrictions range from those met by simple inspection to those that impose requirements to meet complex quarantine rules in the country of origin.

Members of the WTO are required under the 1994 Agreement on Sanitary and Phytosanitary Measures (WTO, 2006) to establish national SPS measures consistent with international standards. International Standards for Phytosanitary Measures (ISPM) 2 Framework for pest risk analysis, established by the International Plant Protection Convention (IPPC, 2007), provides the basic structure to be used by countries when evaluating specific pest risks. ISPM 11, Pest risk analysis for quarantine pests including analysis of environmental risks and living modified organisms, outlines a detailed series of steps to be taken when a country is considering whether a certain insect, disease, or plant species should be subjected to quarantine regulation (IPPC, 2004). A formal pest risk analysis (PRA) includes an assessment of whether the climate in the importing country is suitable for the species' establishment and spread.

Codling moth (CM), a destructive fruit pest, is now found in most of the temperate fruit-growing regions of the world, including Europe, China, Australia, New Zealand, South America, and North America [CAB International (CABI), 2007; Shel'deshova, 1967]. In those areas, it has evolved a synchrony with its hosts, which undergo a period of endodormancy (winter rest) that is paralleled by diapause in the $\mathrm{CM}$ population, triggered by shorter daylengths in late summer (Riedl, 1983). CM diapause is perhaps one of the most studied in the Torticidae. Dickson (1949) first demonstrated that larvae entered "a state of physiological arrest called diapause under the influence of decreasing day length." This biologically active daylength is termed the critical

\begin{tabular}{llll}
\hline $\begin{array}{l}\text { Units } \\
\begin{array}{l}\text { To convert U.S. to SI, } \\
\text { multiply by }\end{array}\end{array}$ & U.S. unit & SI unit & $\begin{array}{l}\text { To convert SI to U.S., } \\
\text { multiply by }\end{array}$ \\
\hline 0.4047 & acre $(s)$ & ha & 2.4711 \\
$\left({ }^{\circ} \mathrm{F}-32\right) \div 1.8$ & ${ }^{\circ} \mathrm{F}$ & ${ }^{\circ} \mathrm{C}$ & $\left(1.8 \times{ }^{\circ} \mathrm{C}\right)+32$
\end{tabular}


photoperiod. Critical photoperiod is that daylength at which $50 \%$ of the population is induced to enter diapause. The length of the critical photoperiod for CM at varying latitudes has been studied extensively (Shel'deshova, 1967). In Washington state growing areas, the critical photoperiod is about $15.5 \mathrm{~h}$, which usually occurs around 15 Aug. Diapause completion is prompted by exposure to environmental conditions in geographic locations where temperatures at ground level do not exceed $10{ }^{\circ} \mathrm{C}$ for at least 1 month of the year (Shel'deshova, 1967). Reviews of the CM diapause literature by Riedl (1983) and Shel'deshova (1967) present the hypothesis that the confirmed distribution of CM is roughly limited by a combination of short daylengths in the tropics (that would continuously induce diapause in the larvae) along with the lack of chilling temperatures to release $\mathrm{CM}$ larvae from diapause. These physiological requirements of the insect theoretically limit natural CM distribution to regions approximately at or greater than $30^{\circ}$ lat., where regular annual fluctuations in daylength and colder temperatures occur. The reader is referred to Riedl (1983) and Shel'deshova (1967) for a more detailed discussion.

Assuming the pest is not found in the importing country and given the demands of meeting the requirements of the PRA process, sometimes the decision to impose quarantine measures is simply based on whether hosts of a particular pest are found in the country. This determination is then combined with some assessment of the relative potential damage caused by the pest where it does occur. CM is an insect pest that has, at times, met this simple test of absence and theoretical economic importance when quarantine decisions have been made in tropical/ subtropical regions (Purdue University, 2008).

However, complicating this simple assessment, growers and researchers have pushed the zone of cultivation of $\mathrm{CM}$ hosts into the tropics and subtropics, through the use of low chilling cultivars, high elevation planting sites, or by applying a range of treatments to the hosts to "replace" or partially replace endodormancy and trigger a new cycle of growth and fruiting (Westwood,
1993). These technologies, ranging from relatively simple chemical treatments to those that are highly complex and labor intensive, such as total removal by hand of apple leaves in Indonesia to annual dormant budding of prechilled flower buds on low elevation pear (Pyrus pyrifolia) trees in Taiwan (Byrne et al., 1995; Janick, 1974; Sauer, 1973; Westwood, 1993), allow growers in those regions to produce temperate fruit for research, personal consumption, and local markets in areas climatically far removed from the crop's predominant production areas. About 15 countries in the tropics and subtropics (Byrne et al., 1995; Westwood, 1993; Willett, 2007) note significant acreage of potential CM hosts, including Taiwan (lat. $23^{\circ} 30^{\prime} \mathrm{N}$ ), which reports over 11,000 ha of potential hosts (Council of Agriculture, 2007). With the temporary closure of Taiwan's market to U.S. apples in 2002 and again in the 2004-05 shipping season due to the detection of CM in apples arriving from the United States, CM restrictions in low latitude countries first created substantial negative economic impacts to U.S. fruit growers (Warner, 2003). Given the hypothesis that the likelihood of CM establishing in the tropics/subtropics was low (Riedl, 1983; Shel'deshova, 1967), further investigation into these concerns was requested by apple growers and their representatives from the Pacific northwestern United States and California.

Complicating the hypothesis (and noted by Taiwan's national plant protection organization, NPPO, in defense of their restrictions), official sources of pest distribution (CABI, 2007) did report the presence of CM in certain low latitude countries. At the time we initiated this assessment, $\mathrm{CM}$ was reported to occur in the tropical/subtropical countries of Bolivia, Colombia, Mauritius, and Peru (CABI, 2002), all countries that also grow fruit species reported as CM hosts. In this work, we describe how a tree fruit industry organization, NHC, in cooperation with U.S. Department of Agriculture (USDA), undertook an assessment of the world CM distribution literature to determine if the reports of CM in tropical countries could be confirmed. This work is part of ongoing efforts by U.S. apple industry organizations and USDA, Animal and Plant Health Inspection Service (APHIS) in support of a PRA process that we believe would justify the elimination of economically damaging phytosanitary restrictions should CM be detected in fruit upon arrival in low latitude countries.

\section{Materials and methods}

Pest distribution Databases. We reviewed the worldwide $\mathrm{CM}$ distribution reports along with any original research cited in those distribution reports from pest databases such as those maintained by CABI $(2002,2007)$ and the European and Mediterranean Plant Protection Organization (EPPO) (2007). International regulatory officials rely heavily on these publications, which are generally considered the most authoritative sources when assessing pest distribution.

INSECT-SPECIFIC RESEARCH. Because CM is a key pest in pome fruit production systems, its literature is extensive. We specifically reviewed the literature on CM distribution, diapause initiation, termination, and ecological adaptability.

LOW LATITUDE FRUIT GROWING. We searched the general horticultural literature looking for reports regarding temperate fruit growing in those tropical and subtropical countries where CM was reported to occur. The proceedings of the International Society for Horticultural Science (ISHS) temperate zone fruit in the tropics and subtropics workgroup were particularly useful in gaining a window into reported pest problems affecting pome fruit when grown at low latitudes. Reports on the production of temperate fruit in these regions were often accompanied by lists of the pests encountered. While not definitive, these articles represent a form of general surveillance (IPPC, 1998) for the pest that can be used in the analysis of distribution records.

NPPO CONTACT. Where reports were identified from countries in the tropics or subtropics without substantive supporting documentation or where conflicting evidence existed, direct contact was made with the NPPO in that country to confirm or refute the presence of CM. Because direct contact with a foreign NPPO is most appropriately made on a government-to-government basis, 
we requested that the USDA APHIS staff and its International Service (IS) regional directors make the inquiries and gain the required information in each country. Once IS in each region was briefed as to the background of the request and the importance of the inquiry to international trade, its staff identified appropriate technical contacts among their counterparts in the countries of interest and relayed the responses to the authors. All of these approaches were used to generate an updated map of worldwide CM distribution.

\section{Results and discussion}

Worldwide surveys of CM distribution (CABI, 2002, 2007) generally agree with the geographic limits described by Shel'deshova (1967). However, anomalous reports from the countries of Bolivia, Colombia, Mauritius, and Peru exist as exceptions to this theoretical distribution and were individually investigated. In each case when reviewing the sources for the CABI (2007) database listings, the distribution data for each country was attributed to EPPO with no specific literature citations. When the EPPO pest distribution database was consulted (EPPO, 2007), the entry for each country was supported by the notation "Present, no details." In the absence of specific survey information and/or if reports in the literature appeared to be ambiguous, we deferred to the knowledge base of the country's NPPO. It has been the experience of the first author that, without additional compelling evidence to the contrary, the judgment of the NPPO regarding pest presence/absence is considered authoritative by U.S. officials.

CM was reported to occur on peach (Prunus persica) in the first half of the 20th century on Mauritius (lat. $21^{\circ} \mathrm{S}$ ), off the southeastern coast of Africa, by officials of the Mauritius Department of Agriculture (D'Emmerez de Charmoy, 1918; D'Emmerez de Charmoy and Gebert, 1921; Moutia, 1943). D'Emmerez de Charmoy and Gebert (1921) noted that an average of $75 \%$ of the fruit was infested by an insect identified as CM but provided no details on collection or identification. This level of infestation on peach is not typical given that specific control of CM in peach orchards is not recommended, even in areas where CM is endemic (Washington State University, 2008), as infestation is rare. Further investigation by USDA APHIS IS personnel in Pretoria, South Africa, assisted by colleagues in Mauritius' NPPO, resulted in a report that "according to entomological records and from authoritative sources within the (Mauritius) Department of Agriculture, codling moth is NOT found in Mauritius" (K. Nagata, personal communication).

CM was also reported from South America by CABI (2002, 2007) occurring in Bolivia, Colombia, and Peru. Bolivia (lat. $17^{\circ} \mathrm{S}$ ) and Peru (lat. $10^{\circ} \mathrm{S}$ ) do have mountainous areas where temperatures can consistently drop below $10^{\circ} \mathrm{C}$, but Colombia (lat. $4^{\circ} \mathrm{N}$ ) does not (Shel'deshova, 1967). Shel'deshova (1967) notes that Garces and Gallego (1947) reported that the predominant host of the insect identified as CM in Colombia is lemon drop mangosteen (Garcinia madruno). Given this unlikely host shift, it is probable that the insect identified as $\mathrm{CM}$ is another species - a position that is apparently held by Colombia's NPPO. Columbia currently regulates imports of pome and stone fruit for CM, citing its absence in that country (USDA APHIS PPQ, 2008). Additionally, Fischer (1992) and Silva (1992), reporting on the cultivation of temperate fruit in Colombia, including apples, do not note CM as a pest of those crops.

After direct contact by USDA APHIS IS with the Bolivian government, the CABI report of CM occurring in Bolivia could not be confirmed by that country's NPPO (C. Cohen, personal communication). Other than the $\mathrm{CABI} / \mathrm{EPPO}$ listing, no other independent reports of CM occurrence in Bolivia were found. Based on the above information, Bolivia, Colombia, and Mauritius should be considered for removal from the list of countries where CM is known to occur because we can find no direct information to confirm the presence of CM in these countries.

Aguilar (1964) reported trapping a moth identified as CM in apple orchards of Peru's Mala Valley during the months of November, December, and early January. This report needs further validation as the method of trapping used (molasses bait traps) is not specific to CM. The Mala Valley is south of Lima about latitude $12^{\circ} \mathrm{S}$ to $13^{\circ} \mathrm{S}$. Bederski (1988) reported that CM was a pest in coastal Peru orchards located between latitudes $9^{\circ} \mathrm{S}$ and $18^{\circ} \mathrm{S}$ at elevations between 50 and $1500 \mathrm{~m}$. He also notes that minimum night temperatures never drop below about $7.2{ }^{\circ} \mathrm{C}$ and that accumulation of chilling temperatures below $10{ }^{\circ} \mathrm{C}$ are rare. Duarte (1992), in his summary of fruit growing in Peru, noted that cooler temperatures may occur but does not note CM attacking apple in that country. $\mathrm{CM}$ is reported to occur in Peru by its NPPO, but no official survey data were available (C. Cohen, personal communication). Further work is needed to substantiate these two positive reports because, if $\mathrm{CM}$ does occur in Peru, it would be the only verified occurrence in the world at these latitudes. We have initiated contact with the government of Peru to determine the possibility of conducting a cooperative trapping effort for CM using pheromone lures in the Mala Valley to verify the older reports. However, the possible presence of CM in Peru cannot be discounted at this time.

The states of Parana, Rio Grand do Sul, and Santa Catarina in Brazil have been added to the worldwide distribution of CM. In a recent notification to the WTO, the government of Brazil (WTO, 2007) notes that CM occurs in the urban areas of three municipalities; Lages, in Santa Catarina, and Caxias do Sul and Vacaria, in Rio Grande do Sul, and is under official control in those areas. All three communities are connected by the same national highway (BR $116)$ and are located at latitudes at or greater than $27.5^{\circ} \mathrm{S}$.

This revised understanding of CM distribution generally supports the hypothesis that the potential for CM establishment appears to be restricted under daylength and temperature conditions encountered in subtropical and tropical regions of the world. Figure 1 (after Shel'deshova, 1967) shows the worldwide distribution of CM (dark gray) along with those countries in the tropics where CM hosts are grown and the pest is not known to occur (wavy). As noted, the reports from Peru (light gray) would benefit from additional confirmation. From this map, it is clear that, while CM has 


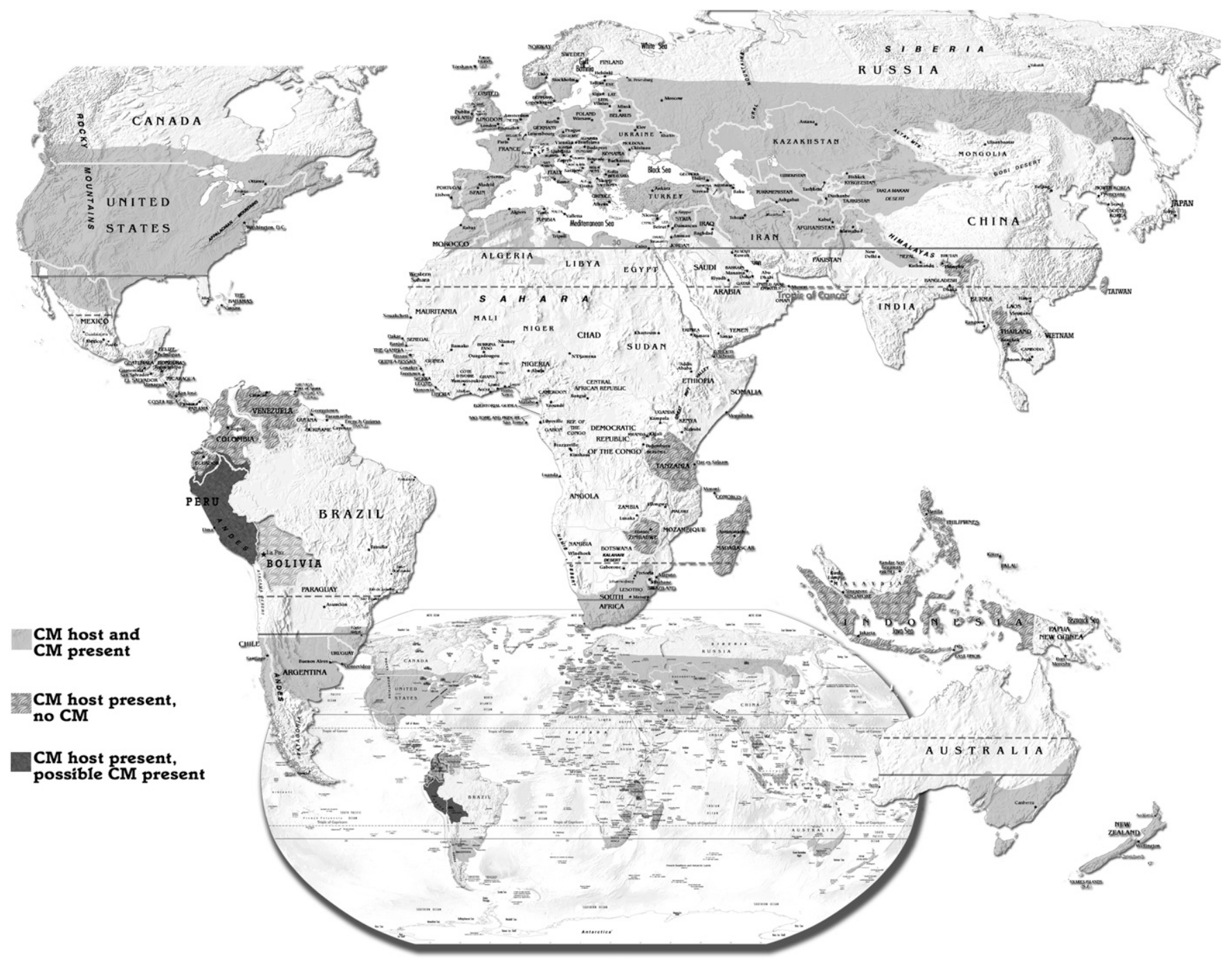

Fig. 1. Worldwide distribution of codling moth (CM) hosts (dark gray and wavy shading) and verified reports (dark gray) of CM distribution. The countries highlighted in wavy shading are those reporting the presence of CM hosts but no verified reports of the pest. The report of CM in Peru (light gray) is the only unrefuted report of CM in the world at that latitude (after Shel'deshova, 1967).

closely followed the spread of its hosts in temperate regions, this same spread has not contiguously occurred as pome fruit production moved into the tropics. Those horticultural techniques used to produce temperate fruit at low latitudes apparently do not create suitable conditions for CM establishment and spread, as it is the plant's response to the environment that is being modified, not the environment itself.

The approach described here to verify the distribution of an important tree fruit pest could be applied to other arthropod pests, such as the temperate zone fruit flies (Rhagoletis spp.), when exporting organizations are faced with restrictions in markets with widely different climates and environmental conditions than those that occur in the production areas of the exporting country. Obviously, to make these types of ecological nonadaptability arguments, the pest of concern should be one of historically broad interest to growers, researchers, and members of the regulatory community to produce the most robust risk assessment. Additionally, it is critical that, when discrepancies in pest distribution reports are identified, the information is provided to recognized databases such as the CABI Crop Protection Compendium and, where possible, published in appropriate venues. It has been the experience of the first author that plant quarantine officials need to be able to cite official and/or scientifically recognized sources to protect themselves from domestic criticism should they change product entry rules based on new information.

\section{Literature cited}

Aguilar, P.G. 1964. Control de la polilla del manzano (Carcocapsa pomonella L.) en el valle de Mala. Revista Peruana de Entomologia 7:103-105.

Bederski, K.A. 1988. Apple growing in the coastal areas of Peru. Acta Hort. 232:51-55.

Byrne, D.H., S. Oh, and J.B. Storey. 1995. Annual grafting of nashi pear in low chill areas of Taiwan. Fruit Var. J. 49:103-106.

C.A.B. International. 2002. Crop protection compendium. CAB International. Wallingford, UK. 
C.A.B. International. 2007. Crop protection compendium. CAB International. Wallingford, UK.

Council of Agriculture. 2007. Yearly report of Taiwan's agriculture. 19 Jan. 2009. <http://english.coa.gov.tw/ list.php? catid=8821>.

D'Emmerez de Charmoy, D. 1918. Annual report of the Department of Agriculture. Mauritius Dept. Agr. Div. Biol. Annu. Rpt. 1918:10-12.

D'Emmerez de Charmoy, D. and S. Gebert. 1921. Insect pests of various minor crops and fruit trees in Mauritius. Bull. Entomol. Res. 12:181-190.

Dickson, R.C. 1949. Factors governing the induction of diapause in the oriental fruit moth. Ann. Entomol. Soc. Am. 42:511-537.

Duarte, O. 1992. El cultivo de los frutales caducifolios en Peru. Acta Hort. 310:35-39.

European and Mediterranean Plant Protection Organization. 2007. Plant Quarantine Data Retrieval System. I Mar. 2009. <http://www.eppo.org/DATABASES/pqr/pqr.htm>.

Fischer, G. 1992. Estado actual y desarollo del cultivo de frutales caducifolios en Boyaca, Columbia. Acta Hort. 310:4149.

Garces, O.C. and F.L. Gallego. 1947. Algunos enfermedales y plagas que atacan al manzano en Antioquia. Revista Facultad Nacional Agronomia, Medellin 7: 443-494.
International Plant Protection Convention. 1998. ISPM 6: Guidelines for surveillance. United Nations Food and Agriculture Organization, Rome.

International Plant Protection Convention. 2004. ISPM 11: Pest risk analysis for quarantine pests including analysis of environmental risks and living modified organisms. United Nations Food and Agriculture Organization, Rome.

International Plant Protection Convention. 2007. ISPM 2: Framework for pest risk analysis. United Nations Food and Agriculture Organization, Rome.

Janick, J. 1974. The apple in Java. HortScience 9:13-15.

Moutia, A. 1943. The commoner insect pests of orchards, food crops, vegetable and flower gardens in Mauritus. Bul. Dept. Agr. Mauritius Gen. Ser. Port Louis, Mauritius.

Northwest Horticultural Council. 2008. Industry fact sheets. 30 Dec. 2008. <http://www.nwhort.org/nhcpublic/ fact-sheets.html>.

Purdue University. 2008. Center for Environmental and Regulatory Information Systems. Purdue University. 1 Mar. 2009. <http://ceris.purdue.edu/ceris > .

Riedl, H. 1983. Analysis of codling moth phenology in relation to latitude, climate and food availability, p. 233-252. In: V.K. Brown and I. Hodek (eds.). Diapause and life cycle strategies in insects. Dr. W. Junk, The Hague, The Netherlands.
Sauer, M. 1973. Successful apple growing in tropical Indonesia. Fruit Var. J. 27:44-45.

Shel'deshova, G.G. 1967. Ecological factors determining distribution of the codling moth, Laspeyresia pomonella L. (Lepidoptera: Tortricidae), in northern and southern hemispheres. Entomol. Rev. (Engl. Transl.) 46:349-361.

Silva, B.E. 1992. Diagnosticos y perspectives de las regions productoras de frutales caducifolios en Columbia. Acta Hort. 310:51-57.

Warner, G.E. 2003. Industry hopes Taiwan rules will be relaxed. Good Fruit Grower 54(4):11

Washington State University. 2008. 2008 crop protection guide for tree fruits in Washington. EB0419. Washington State Univ. Ext. Bul. EB0419.

Westwood, M.N. 1993. Temperate zone pomology: Physiology and culture. 3rd ed. Timber Press, Portland, OR.

Willett, M.J. 2007. Growing pears in Taiwan. Good Fruit Grower 57(15):12.

World Trade Organization. 2007. Notification G/SPS/N/BRA/374. 14 Dec. 2007. I Mar. 2009. <http://docsonline. wto.org/DDFDocuments/t/G/SPS/ NBRA374.doc $>$.

World Trade Organization. 2009. The WTO agreement on the application of sanitary and phytosanitary measures (SPS Agreement). 13 Jan. 2009. <http:// www.wto.org/english/thewto_e/whatis_ e/tif_e/agrm4_e.htm $>$. 